\title{
Impact of Continuing Pharmacy Education on the Knowledge, Attitude and Practice of Community Pharmacists about ADR Monitoring and Reporting
}

\author{
M. DEEPALAKSHMI, PREETHI KUMAR, K. P. ARUN AND S. PONNUSANKAR* \\ Department of Pharmacy Practice, JSS College of Pharmacy, A Constituent College of JSS Academy of Higher Education and \\ Research, Ooty-643 001, India
}

Deepalakshmi et al.: Impact of CPE on ADR Monitoring for Community Pharmacists

\begin{abstract}
The present study was aimed to train the community pharmacists in pharmacovigilance and implement adverse drug reaction monitoring and reporting program in their practice. Continuing pharmacy education programs about adverse drug reaction monitoring and reporting were conducted periodically to the community pharmacists both in the study centre and respective pharmacies and their knowledge, attitude, practice were assessed both prior and post education program through a self-administered questionnaire. The participants were followed-up after 6 months to assess the changes if any in their practice. Pharmacists' awareness about the concept of adverse drug reaction reporting, which form to use for reporting adverse drug reactions, how and where to report adverse drug reactions have significantly increased $(p<0.05)$ to $100 \%$ in the post continuing pharmacy education survey from 84, 45, 51 and $36 \%$ during pre-continuing pharmacy education survey, respectively. The knowledge about all the stakeholders of health such as doctors, pharmacists, nurses and patients to report adverse drug reactions also increased from 31 to $100 \%$ (p<0.05) from pre continuing pharmacy education to post test. In the post continuing pharmacy education survey, $100 \%$ of the respondents agreed that reporting adverse drug reactions is necessary. Majority of respondents (72.7\%) strongly agreed that adverse drug reactions reporting is a part of professional role. In the repeat survey conducted after 6 months, $11 \%$ of respondents reported that they have a system of monitoring and reporting adverse drug reactions in their pharmacies in comparison to $0 \%$ at the baseline, which was prior to continuing pharmacy education program and adverse drug reactions from 25 patients were reported to pharmacovigilance program of India by these pharmacists through the investigators of this study. The continuing pharmacy education program resulted in improvement of knowledge, attitude and practice of monitoring and reporting adverse drug reaction among community pharmacists as well as implementation of adverse drug reaction monitoring services in selected community pharmacies in the study region.
\end{abstract}

Key words: ADR monitoring and reporting, community pharmacists, continuing pharmacy education, knowledge, attitude, practice, pharmacovigilance

Adverse drug reactions (ADRs) are the most common causes of morbidity, mortality and poor economical outcomes. Therefore post marketing surveillance is very important for monitoring the risks and benefits of pharmaceutical products after they have been marketed. The roles of pharmacists have expanded to other aspects of patients' care, which include reporting ADR, improving patients' health and economic outcomes ${ }^{[1]}$. The pharmacists traditionally have been playing the role of preparing and dispensing medications, with no or minimal emphasis on providing services to the patients $^{[2]}$. Pharmaceutical care is a patient centric and outcome oriented process that requires the direct

*Address for correspondence E-mail: drsponnusankar@jssuni.edu.in

July-August 2019 involvement of pharmacists with the patients to prevent diseases, promote health and drug therapy monitoring to assure the safety and efficacy of medications ${ }^{[3]}$. Community pharmacy as healthcare organization has a greater scope for providing trustworthy support and advice on health and drugs to people and delivery of such professional services by community pharmacies shall

This is an open access article distributed under the terms of the Creative Commons Attribution-NonCommercial-ShareAlike 3.0 License, which allows others to remix, tweak, and build upon the work non-commercially, as long as the author is credited and the new creations are licensed under the identical terms

Accepted 26 May 2019

Revised 07 February 2019

Received 06 November 2018

Indian J Pharm Sci 2019;81(4):633-639 
contribute to improving health outcomes ${ }^{[4,5]}$. Assessing the knowledge, attitude and practice of community pharmacists relating to spontaneous reporting of ADRs is very important. When pharmacists have sufficient knowledge about ADR reporting process, they can also improve other healthcare professionals' knowledge about ADR reporting ${ }^{[6]}$. In India, studies pertaining to ADR reporting in community set-up are found to be limited due to poor knowledge about the professional obligations and community pharmacists are confined only to the trade. As adequate motivation to community pharmacists will strengthen the reporting system, there is a need for designing and implementing the ADR monitoring and reporting system in community pharmacies ${ }^{[7]}$. In these contexts, the present study was designed to educate and train the community pharmacists in pharmacovigilance services through continuing pharmacy education (CPE) and assess the knowledge, attitude and practice of ADR monitoring and implementation of ADR reporting in their practice.

\section{MATERIALS AND METHODS}

This was a prospective interventional community study conducted at Nilgiris district in the southern part of India for a period of six months. A 26-item selfadministered questionnaire was designed to record participants' knowledge, attitude and practice about ADRs and barriers to their reporting. The questionnaire was designed based on the previously published studies $^{[8-10]}$ that contained seven items to assess the pharmacists' knowledge about ADR, its reporting procedures, eight items to evaluate the pharmacists' attitude towards ADR reporting and eleven items for assessing their practice towards ADR monitoring apart from few questions to capture the relevant demography of the respondents. While many of the questions were given with multiple choice answers from which the respondents were expected to select any one answer, which would be most appropriate and five questions towards assessing the attitude had options viz. strongly agree, agree, not sure, strongly disagree and disagree.

CPE program was designed for community pharmacists to educate and train them in ADR monitoring and reporting services and the information about the conduct of CPE was disseminated through pamphlets. The contents of the educational material were customized to include the issues on pharmacovigilance and need for ADR reporting in the community setting. The materials were delivered through didactic lectures, demonstrations, and interactive discussions conducted periodically to the community pharmacists both in the study center and respective pharmacies so as to provide the participants, the knowledge about pharmacovigilance concepts and the necessary skills to monitor and report ADRs. The key learning objectives of the CPE program included understanding the epidemiology of ADRs and drug safety, highlighting the concepts of pharmacovigilance, pharmacists' roles in ADR monitoring and reporting, current scenario in India and importance of reporting ADRs by community pharmacists.

In the $\mathrm{CPE}$ program, $\mathrm{ADR}$ reporting form and $\mathrm{ADR}$ documentation form were distributed to the pharmacists and demonstrations were given for filling the same. Earlier, the theoretical concepts of ADR monitoring included WHO definition of the ADR, how to report the ADRs, where to report the ADRs, causes of the ADRs, risks factors of ADRs, how to assess the causality of the ADRs and the role of pharmacists in preventing and reporting of ADRs were delivered through appropriate audio visual aided lectures. ADR awareness posters were also prepared and distributed for displaying in prominent places at community pharmacies, which most of the customers could visualize and become aware of this service.

Pre-evaluation was done through the questionnaire in order to assess the baseline knowledge, attitude and practice of the community pharmacists about ADR monitoring and reporting system. After the CPE program, the same questionnaire was administered to assess the outcome to find out improvement, if any in the knowledge and attitude of the participants towards ADR monitoring and reporting. The same questionnaire was also administered at the end of six months especially to assess the change in their practice which would have not been captured in the post test immediately after CPE.

Content validity and reliability of the questionnaire was evaluated through a pilot survey done on 5 pharmacists to assess the face validity of the tool. Furthermore, Cronbach's $\alpha$ was calculated using the reliability scale. The overall $\alpha$ value was calculated as 0.7 .

The study was approved by the Institutional Review Board (IRB) of JSS College of Pharmacy, Ooty and all participants gave written informed consent prior to interviews or survey participation. Questions that could disclose the personal identity of the pharmacists or pharmacies (i.e. names, contact numbers, name of pharmacy) were avoided. 
Registered pharmacists practicing in community pharmacy and who consented to monitor and report the ADRs were included in this study and they were excluded for incomplete responses if any. A cross sectional study evaluating the pattern of ADRs was carried out by analysing the filled ADR reporting forms received from the community pharmacists. The reporting form had information on the reporter, the patient details and information on the reaction and medications. During the study period, clinical pharmacists from the institution where the research was carried out visited trained community pharmacists on alternate days and collected the filled ADR reporting forms if any. Any additional guidance needed for the community pharmacists were provided by the visiting clinical pharmacists. All the ADRs monitored and recorded by the community pharmacists were collected. The demographic details were analysed. The causality and severity assessments were carried as per the WHO and modified Hartwig and Siegel scales, respectively.

Data analysis was done using the Statistical Package for Social Science (SPSS) Release 21. Both descriptive and inferential statistics were used wherever appropriate. Frequencies and percentages were used to describe the respondents' demographic information and professional characteristics. A p-value of 0.05 or less was considered to be significant.

\section{RESULTS AND DISCUSSION}

Out of about 60 community pharmacists approached for participation in the $\mathrm{CPE}$, a total of 55 community pharmacists turned up for the CPE program and successfully completed the study as per the inclusion and exclusion criteria. Out of these 55 community pharmacists, only 6 pharmacists commenced their practice of ADR monitoring and reporting even after 6 mo from the completion of the CPE.

Of these 55 respondents, $47(85 \%)$ were male. The age of the respondents ranged from 22 to $63 \mathrm{y}$ and majority of the respondents aged between 41-50 y (42\%) and about $91 \%$ of the respondents were found to have diploma in pharmacy (D. Pharm.) qualification (Table 1).

Pharmacists' knowledge about the concept of ADR reporting, form used for ADR reporting, how and where to report ADRs have significantly $(p<0.05)$ increased to $100 \%$ in the post CPE survey from 84 , 45, 51 and $36 \%$ during pre CPE survey, respectively (fig. 1A). The knowledge that all the stakeholders of health that include doctors, pharmacists, nurses and patients can report ADRs has also increased from 31 to $100 \%$ from pre CPE to post-test with statistical significance $(\mathrm{p}<0.05$; fig. $1 \mathrm{~B})$.

Prior to CPE, none of the pharmacists' chosen the option of need for reporting ADRs associated with herbal medicines and at post CPE survey $100 \%$ pharmacists agreed upon the requirement of reporting ADRs for medical devices, vaccines and blood products and allopathic medicines, which is depicted in fig. 2 and these differences were found statistically significant $(p<0.05)$.

In the post CPE survey, $100 \%$ of the respondents agreed that reporting ADR is necessary. Majority of the respondents (64\%) agreed ADR reporting should

TABLE 1: SOCIO-DEMOGRAPHIC DETAILS OF THE COMMUNITY PHARMACISTS

\begin{tabular}{lcc}
\hline Demographics & Numbers & Percentage \\
\hline Age in years & & \\
\hline $21-30$ & 06 & 10 \\
$31-40$ & 18 & 32 \\
$41-50$ & 23 & 42 \\
$>50$ & 09 & 16 \\
Sex & & \\
Male & 47 & 85 \\
Female & 8 & 15 \\
Qualification & & \\
Diploma in Pharmacy & 50 & 91 \\
Bachelor in Pharmacy & 05 & 09 \\
\hline
\end{tabular}

A.
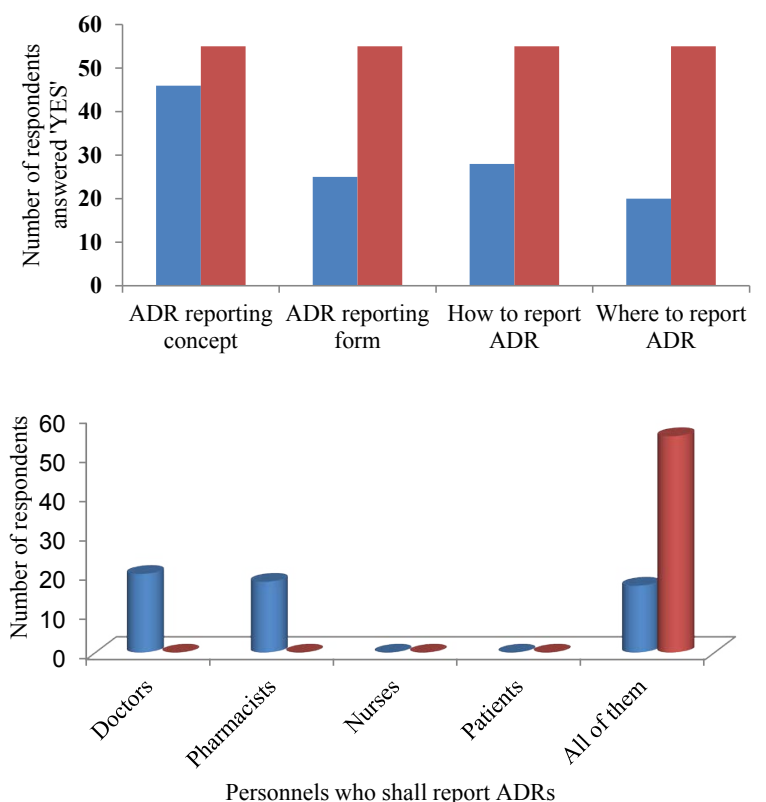

Fig. 1: Knowledge of community pharmacists pre and post CPE Knowledge of community pharmacists about A. ADR monitoring and reporting and $B$. on who shall report ADRs assessed ( $\square$ ) Pre-CPE and ( $\square$ ) post-CPE 
be made mandatory and $100 \%$ of the respondents were interested to attend a course to improve their ability of spontaneously reporting ADRs of the patients approaching their pharmacy wherein only $69 \%$ were interested prior to CPE that was significantly less (p<0.05; fig. 3).

Prior to CPE about $82 \%$ of the respondents opined that availability of reporting forms was the barrier and post CPE, only $18 \%$ continued to feel that the same as a barrier $(\mathrm{p}<0.05)$. Availability of time was felt as the barrier by almost half of the respondents both at pre and post CPE (55 and $51 \%$ respectively; $p>0.05$ ). Sixty four percent of them felt lack of motivation as the barrier for reporting ADRs prior to CPE was reduced to $18 \%$ post CPE ( $p>0.05)$. About $73 \%$ of them claimed that lack of knowledge as a barrier prior to CPE and that was reduced significantly $(\mathrm{p}<0.05)$ to $13 \%$ in the post CPE survey (fig. 4).

Majority of respondents i.e., $72.7 \%$ strongly agreed that ADR reporting is a part of professional role; $81.8 \%$ of respondents strongly agreed that reporting ADRs is necessary for newer drugs. $76.3 \%$ of pharmacists strongly agreed that reporting of ADRs is necessary for serious ADRs. Eighty percent of respondents strongly agreed that reporting of ADRs is necessary for well recognized ADRs. Majority of respondents $(78.1 \%)$ strongly agreed that reporting of ADR should be voluntary (fig. 5).

In the repeat survey conducted after 6 mo, $11 \%(n=6)$ of respondents reported that they have a system of monitoring and reporting ADR in their pharmacies in comparison to $0 \%$ at the baseline, i.e., prior to $\mathrm{CPE}$ program. All these pharmacists were male and in the age group of 31-40 y.

ADRs from 25 patients comprising 14 male and 11 female were reported by 6 community pharmacists.

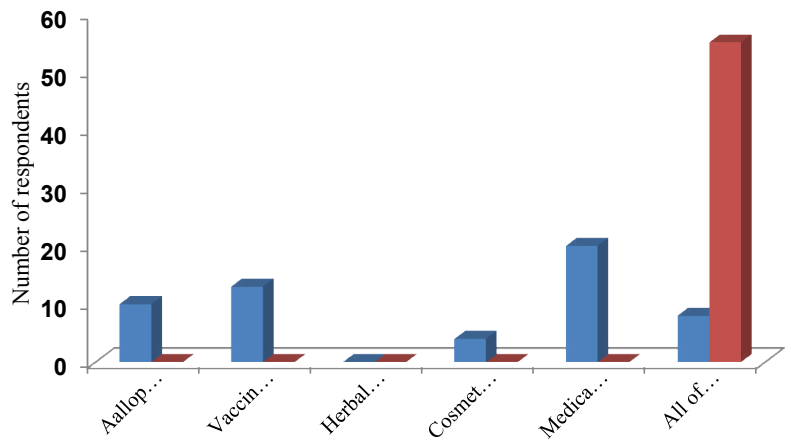

Fig. 2: Knowledge on different sources causing ADRs that require reporting ( $\square$ ) Pre-CPE, ( $\square$ ) post-CPE

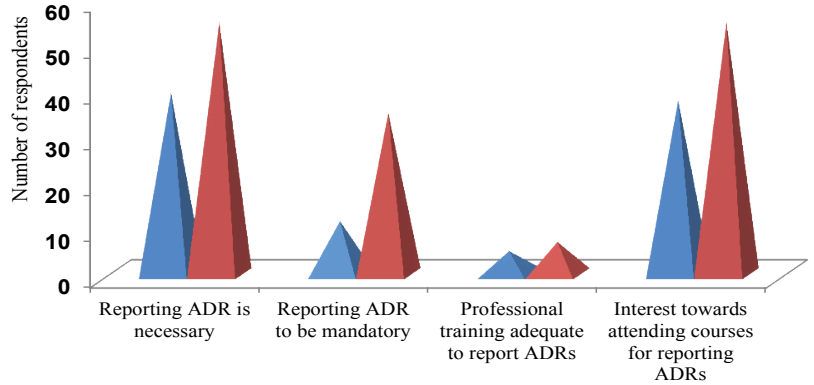

Fig. 3: Attitudes of the responders about ADR monitoring and reporting

( $\square$ ) Pre-CPE, ( ) post-CPE

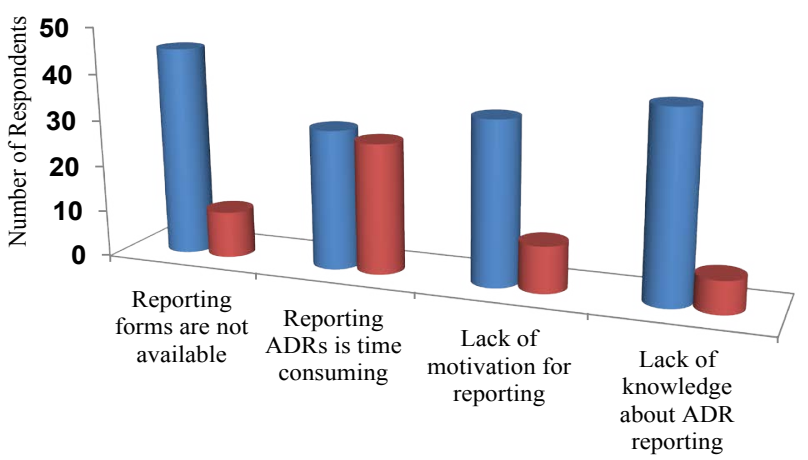

Fig. 4: Barriers to ADR monitoring and reporting in community pharmacy

(घ) Pre-CPE, (घ) post-CPE

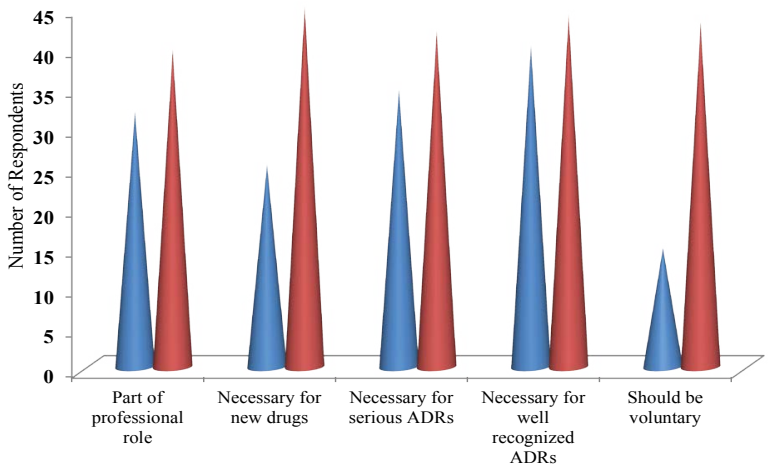

Fig. 5: Attitude of community pharmacists about reporting ADRs

( $\square)$ Pre-CPE, ( $\square$ ) post-CPE

The age of the patients encountered the ADRs ranged between 30-59 y. The therapeutic classes of drugs associated with these ADRs and the various biological systems associated with such ADRs are shown in Tables 2. Causality assessment for the reported ADRs was done by using WHO scale and results are presented in Table 3. The severities of the suspected ADRs were assessed using modified Hartwig and Siegel Scale.

The pharmacovigilance program of India (PvPI) requires all health care professionals to be involved in the monitoring and reporting of ADRs, but the responses towards their expectations are very limited 
TABLE 2: THERAPEUTIC CLASSES OF DRUGS AND BIOLOGICAL SYSTEMS/DISORDERS ASSOCIATED WITH ADRs REPORTED

\begin{tabular}{lcc}
\hline Drug & Number of patients & Percentage (\%) \\
\hline Antibiotics & 09 & 36 \\
NSAIDs* & 06 & 24 \\
Anticancer & 01 & 4 \\
Antidiabetic & 05 & 20 \\
Antihistamine & 01 & 4 \\
Antitubercular & 03 & 12 \\
System & Number of patients & Percentage (\%) \\
\hline Gastro intestinal & $(\mathbf{n}=\mathbf{2 5 )}$ & 40 \\
Peripheral nervous & 01 & 4 \\
Cardio vascular & 09 & 36 \\
Respiratory & 02 & 8 \\
Blood pressure & 02 & 8 \\
Thyroid & 01 & 4 \\
\hline
\end{tabular}

* Non-steroidal antiinflammatory drugs

TABLE 3: CAUSALITY ASSESSMENT OF SUSPECTED ADRS -BY WHO SCALE

\begin{tabular}{lcc}
\hline WHO scale & $\begin{array}{c}\text { Number of } \\
\text { patients }\end{array}$ & Percentage (\%) \\
\hline Certain & 5 & 20 \\
Probable & 8 & 32 \\
Possible & 6 & 24 \\
Unlikely & 0 & 0 \\
Unclassified & 1 & 4 \\
Unclassifiable & 5 & 20 \\
\hline
\end{tabular}

compared with reporting from the developed countries. Though ADR reporting in India has got its momentum as many of the ADRs are being reported from the hospital setting, such activities in the community pharmacy setting is negligible or almost non-existence.

To encourage the community pharmacists towards ADR monitoring and reporting, a CPE specifically on ADR monitoring was conducted and the knowledge, attitude and practice of the study participants were assessed both at pre and post CPE program. Prior to the CPE, about $84 \%$ participants were aware about the concept of ADR reporting and $45 \%$ of them knew about the ADR reporting form to be used. A similar study conducted in Kerala, a neighbouring state had shown that about $45 \%$ of the community pharmacists only knew about ADR reporting concept and procedure to do the same ${ }^{[8]}$. But in a study conducted in Saudi Arabia about $90 \%$ of the pharmacists were not aware of the procedure of ADR reporting ${ }^{[9]}$. However, the CPE program achieved $100 \%$ knowledge among the community pharmacists participated in the study about the concept of ADR monitoring, the forms to be used for reporting, how and where to report the ADRs.
About $33 \%$ responded that community pharmacists shall report ADRs, and post CPE, all of them accepted that pharmacists are competent to report ADRs. The survey conducted in Kerala reported that about $72 \%$ of the pharmacists were aware that the pharmacists were aware about pharmacists' eligibility to report ADRs ${ }^{[8]}$. Another study reported from Saudi Arabia stated only about $40 \%$ of pharmacists claimed that they shall report $\mathrm{ADRs}^{[10]}$.

About $72 \%$ of the respondents expressed ADR monitoring is necessary prior to CPE but $100 \%$ agreement was seen during post CPE. Very importantly, the percentage of respondents both pre and post CPE was not changed much for the question about adequacy of professional training to report ADRs that showed the study participants require more training about ADR monitoring and reporting. This was supported by the response towards the interest to attend courses on ADR reporting by all the participants.

Unavailability of the ADR reporting forms, lack of knowledge and motivation were claimed as the top three (82, 72 and $64 \%$, respectively) barriers for reporting ADRs prior to $\mathrm{CPE}$. The survey conducted among the community pharmacists of Saudi Arabia ${ }^{[8]}$ also ranked the unavailability of ADR reporting forms at second rank. However, the lack of knowledge and motivation has ranked at ninth and sixth, respectively in the said study. During the post CPE survey, lack of knowledge was ranked as a least (13\%) barrier by the respondents followed by lack of motivation (19\%) and unavailability of ADR reporting forms (19\%), which revealed the successful outcome of the CPE in positively influencing the knowledge and attitude of the pharmacists participated the program. However, both pre and post CPE, the participants believed that ADR reporting was time consuming (55 and $51 \%$, respectively).

The participants had a poor attitude about reporting ADRs prior to CPE, which were improved with post CPE. Only about $45 \%$ of the study participants expressed ADR monitoring was necessary for new drugs, prior to the CPE program that was increased to about $82 \%$ during post CPE. Whereas in a study conducted at Oman, $20.5 \%$ of the respondents answered that ADRs to be reported for new drugs ${ }^{[1]}$. Post CPE, almost about $82 \%$ of the study participants responded that ADR reporting is necessary for all new drugs, serious reactions and reactions already recognized. 
About $28 \%$ respondents who said that ADR reporting should be voluntary had increased to $78 \%$ during post CPE. In a study conducted at Bangalore, a metro city in south India, $90 \%$ of the pharmacists agreed that ADR reporting as a voluntary act ${ }^{[12]}$. Nearly about $11 \%$ of the respondents reported that they were practicing ADR reporting after 6 mo of post CPE assessment, which was null at the baseline. These pharmacists reported about 25 suspected ADRs. A survey report revealed that only $8 \%$ of the community pharmacists received ADRs but only $1 \%$ of them reported ADRs ${ }^{[12]}$.

Among the ADRs reported, antibiotics, NSAIDs and antidiabetic agents were found to be the top three therapeutic classes. A study reported from UAE also revealed that antibiotics were the top class of drug for which ADRs were reported in most numbers ${ }^{[9]}$. Another study from Saudi Arabia revealed that NSAIDs and aspirin are the top ranked therapeutic agents caused $\mathrm{ADRs}^{[8]}$. Among the reported ADRs, the system affected by the reaction was found to be the gastro intestinal tract $(40 \%)$ followed by cardiovascular $(36 \%)$. The study reported from Alahsa, UAE also reported GIT as the most frequently affected organ system ${ }^{[9]}$. A study reported from China also claimed that gastro intestinal tract was the organ system mostly (34\%) affected by $\mathrm{ADRs}^{[13]}$.

As per the classifications of $\mathrm{WHO}$, probable ADRs were found more (32\%) followed by possible (24\%) and certain $(20 \%)$. Antibiotics cefixime, ceftriaxone, steroids dexamethasone and methylprednisolone, diuretics frusemide are the drugs caused ADR's categorised as certain. Similar pattern of results were also reported from another study conducted in the nearby city (Coimbatore) with the values of 42, 23 and 30 , respectively ${ }^{[14]}$. These ADRs were found $40 \%$ each as mild and moderate and the severe were only $20 \%{ }^{[15]}$. The study conducted at Coimbatore had shown that $12 \%$ reactions were severe and $49 \%$ were moderate and remaining $39 \%$ were classified as mild ${ }^{[14]}$.

Thus, the CPE program resulted in implementation of ADR monitoring services in selected, limited community pharmacies in the study region. The results of this study is promising and encouraging to involve the community pharmacists in ADR monitoring and reporting. This model of assessing, educating and inculcating the practice of ADR monitoring and reporting among community pharmacists should be carried out in a bigger way as a professional motion across the country by the regional pharmacy colleges, professional bodies and associations for the successful role playing by the community pharmacists in PPI.

\section{Acknowledgement:}

The authors acknowledge the JSS University, Mysore for their permission for the conduct of this work as a part of a Ph.D. dissertation of one of the faculty member.

\section{Financial support and sponsorship:}

Nil.

\section{Conflicts of interest:}

There are no conflicts of interest.

\section{REFERENCES}

1. Edlavitch SA. Post marketing surveillance methodologies. Drug Intell Clin Pharm 1988;22:68-78.

2. Albanese NP, Rouse MJ. Council on Credentialing in Pharmacy, Scope of contemporary pharmacy practice: Roles, responsibilities, and functions of pharmacists and pharmacy technicians Executive summary. J Am Pharm Assoc 2010;50(2):e35-69.

3. van Mil JW, Schulz M, Tromp TF. Tromp, Pharmaceutical care, European developments in concepts, implementation, teaching, and research: a review. Pharm World Sci 2004;26(6):303-11.

4. A Report on Challenges and opportunities for pharmacists in health care in India. South East Asia FIP-WHO Forum of National Pharmaceutical Associations; 2007. [cited 2017 April 10]. Available from: www.searpharmforum.org/EN/ Section10_37.htm

5. Adepu R, Nagavi BG. General practitioners' perceptions about the extended roles of the community pharmacists in the state of Karnataka. Indian J Pharm Sci 2006;68:36-40.

6. Khalili H, Mohebbi N, Hendoiee N, Keshtkar AA, DashtiKhavidaki S. Improvement of knowledge, attitude and perception of healthcare workers about ADR, a pre- and post-clinical pharmacists' interventional study. BMJ Open 2012;2(1):e000367.

7. Rabbur RSM, Emmerton L. An Introduction to adverse drug reaction reporting system in different countries. Int $\mathrm{J}$ Pharm Pract 2010;13:91-100.

8. Salim M, Nimisha Hussain, Balasubramanian T, Lubab M, Nayana SA, Nathaliya PM. The Current Perspective of Community Pharmacists towards Pharmacovigilance. J Pharmacovigil 2015;3:180.

9. Khan TM. Community pharmacists knowledge and perceptions about adverse drug reactions and barriers towards their reporting in Eastern region, Alahsa, Saudi Arabia. Ther Adv Drug Saf 2013;4(2):45-51.

10. Sathvik BS, Chukir DMO, Abo-Aldan E, Soliman MN. Adverse drug reaction monitoring and reporting: Knowledge, attitude and belief of physicians \& pharmacists of Ras Al Khaimah, United Arab Emirates (UAE). Int J Pharm Sci Res 2014;5(2):368-75.

11. Jose J, Jimmy B, Al-Ghailani ASH, Al-Majali MA. A cross sectional pilot study on assessing the knowledge, attitude and 
behavior of community pharmacists to adverse drug reaction related aspects in the Sultanate of Oman. Saudi Pharm J 2014;22(2):163-9.

12. Nagaraju K, Satheesh VK, Shankar U, Banu R. A Study on Creating Awareness of Adverse Drug Reactions in Community Pharmacists in Bangalore. Indian J Pharm Pract 2015;8(2):72-77.

13. Yu YM, Shin WG, Lee JY, Choi SA, Jo YH, Youn SJ, et al. Patterns of Adverse Drug Reactions in Different Age Groups:
Analysis of Spontaneous Reports by Community Pharmacists. PLoS One 2015;10(7):e0132916.

14. Sriram S, Ghasemi A, Ramasamy R, Devi M, Balasubramanian $\mathrm{R}$, Ravi TK, et al. Prevalence of adverse drug reactions at a private tertiary care hospital in south India. J Res Med Sci 2011;16(1):16-25.

15. Hartwig SC, Siegel J, Schneider PJ. Preventability and severity assessment in reporting adverse drug reactions. Am J Hosp Pharm 1992;49:2229-31. 